\title{
Implementing Retail Category Management: a Model-Based Approach to Setting Optimal Markups
}

\author{
Michel Wedel • Jie Zhang • Fred Feinberg
}

Published online: 20 March 2015

(C) Springer Science+Business Media New York 2015

\begin{abstract}
This study proposes a model-based approach for implementing retail category management $(\mathrm{CM})$ with a focus on markup decisions. We construct a Bayesian econometric model that offers a comprehensive portrait of own- and crossprice effects on sales of individual brands in a category, as well as price reactions driven by their manufacturers' price setting behavior. We then derive optimal retail markups of individual brands within a product category by maximizing a retailer's total category profit over a finite time horizon and illustrate the application of the approach using store-level weekly sales data of toothbrushes. Our empirical results indicate that markups on large-share brands should have been higher than in the current practice. In addition, retailers can achieve higher category profits without increases in their overall category sales, but rather by driving reductions in the wholesale prices. We discuss the managerial implications of our approach for retailers and other channel partners.
\end{abstract}

Keywords Category management · Optimal retail markups · Bayesian pooling $\cdot$ Nonparametric smoothing $\cdot$ Global optimization

\footnotetext{
M. Wedel $(\triangle)$

Robert H. Smith School of Business, University of Maryland, 3303

Van Munching Hall, College Park, MD 20742, USA

e-mail: mwedel@rhsmith.umd.edu

J. Zhang

Robert H. Smith School of Business, University of Maryland, 3311

Van Munching Hall, College Park, MD 20742, USA

e-mail: jiejie@rhsmith.umd.edu

F. Feinberg

Stephen M. Ross School of Business, University of Michigan, 701

Tappan Street, Room 5324, Ann Arbor, MI 48109, USA

e-mail: feinf@umich.edu
}

\section{Introduction}

For retailers, category management (CM) is the process of managing product categories as strategic business units and coordinating merchandise assortment, shelf-space allocation, pricing, promotions, and inventory management decisions to achieve the overall objectives for the category [5], where profit maximization is the objective for most categories [12, 22]. $\mathrm{CM}$ has gained popularity because retailers have come to realize that coordination of merchandising decisions across brands leads to increased profit for the category as a whole [27]. CM is a significant departure from the traditional brandbased merchandising management approach and is increasingly adopted by retailers, especially in consumer packaged goods channels. However, in spite of the mounting evidence on the benefits of CM [27], simultaneously setting the prices for an array of products in the category is still one of the most vexing challenges in $\mathrm{CM}$ [7], in part because of a lack of analytical tools to support these pricing decisions.

The main objective of this study is to offer a model-based approach for implementing $\mathrm{CM}$ in response to continued needs in the retail industry. We focus on pricing decisions, and our results suggest that adopting CM-based pricing policies can lead to substantial increases in profitability. We develop a descriptive econometric model that offers a comprehensive picture of own- and cross-price effects on sales for individual brands in a category, as well as of price reactions among the brands. Based on the model, we then derive the optimal markups for all brands in a category simultaneously, such that the retailer's overall category profit over a given time period is maximized. We proceed by reviewing the relevant literature, motivating our approach, detailing the model, describing the optimization procedure, illustrating it with an empirical application, and discussing the managerial implications of our findings. 


\section{Literature Review and Intended Contributions}

Taking a broad perspective on past research, three streams of research are relevant to our study. We briefly review and identify trade-offs of each. The first stream uses a game-theoretic approach to analyzing pricing issues in distribution channels (e.g., $[4,17,20,29,35,51])$. Many studies in this area have focused on manufacturers' price competition and their optimal pricing decisions and analyzed stylized games of firms' behavior to derive equilibrium pricing outcomes. A common feature of these games is that manufacturers and retailers have full information and are assumed to know each other's demand functions and cost structures. These studies offer important theoretical implications for firm behavior when the game setup reflects reality well. For example, Basuroy et al. [4] show that adoption of CM by one retailer may result in higher retail prices and lower sales. Hall et al. [28] find that adopting a CM perspective increases total profit, because a brand-based management perspective results in greater than optimal pass-through of trade promotions. Yet, Ingene and Parry [30] add a note of caution, in that six specific hypotheses about distribution channels suggested by game theoretic analyses failed to generalize beyond the assumptions of the frameworks generating them.

The second stream of research estimates reduced-form models of demand and/or pricing decisions, usually based on store level scanner data (e.g., [7, 10, 21, 34, 37, 43, 48, 49]). These models often take the form of neoclassical log-linear demand systems for differentiated product markets [44]. Sales response models have been used to examine the effects of marketing activities of competitive brands on sales (e.g., [37]), and competitive response models have been used to establish the relationship of a firm's marketing mix on its own and competitors' (lagged) marketing mix variables (e.g., [36]). The emphasis in this stream of research is on empirically estimating demand and/or price reaction functions instead of postulating the decision rules that each firm would, or should, employ. Research in this area has revealed that manufacturers have a tendency to react too quickly and too strongly to competitors' price changes and that short-run changes in market prices are therefore dominated by manufacturers', instead of retailers', reactions to competitive offerings [36]. This has important implications for retailers' category management decisions, which will be reflected in our model specification. Montgomery [37] and Kopalle et al. [34] offer tools to support pricing decisions. Montgomery [37] develops a hierarchical model of the effects of marketing variables on log-sales, extending earlier work of Blattberg and George [10]. Kopalle et al. [34] extend the standard log-log demand function to include dynamic effects of discounting and stockpiling, using a time-varying parameters specification. They estimate a price reaction function based on a Stackelberg leader-follower game, which allows them to determine optimal retailer and manufacturer prices.

The reduced-form approaches have several problems, as well summarized by Reiss and Wolak [44], and Chintagunta et al.
[15]. Potential endogeneity of the marketing mix variables is often ignored in these models. The effects of policy changes cannot be distinguished from changes in the competitive market environment (the Lucas critique). In addition, the number of parameters in these demand models is often prohibitively large and simplifying assumptions are usually made to assist model estimations. Most importantly, for the purposes of implementing $\mathrm{CM}$, the commonly used demand models do not yield interior solutions to profit maximization problems due to their functional forms.

The third stream of research follows the tradition of the empirical industrial organization approach (e.g., $[13,23,25,26,31$, $45,55,57])$. Here, structural models are derived from economic principles ([6], BLP hereafter) and have been applied to marketing problems (e.g., [41]). These models capture demand and supply decisions based on assumptions on individual customer behaviors and the nature of the strategic interactions of players in the market (e.g., $[8,13,16])$. The demand and supply side decisions are separately parameterized, which lends these models to "what if" analyses devoid of the Lucas' critique. Specifically, Chintagunta [13] applies the BLP approach to investigate demand as a function of prices and deals and their interactions, assuming that prices are set by the retailer by optimizing category profits and share of the store brand, while taking into account side payments and store traffic. Several findings from this line of research are particularly relevant here. First, this research has convincingly shown that prices should be incorporated in the demand function specification endogenously (e.g., [8]). Second, Stackelberg price leadership games offer a closer resemblance to real world situations than Bertrand-Nash games [7, 31]. Third, if retailers account for heterogeneity in the marketplace, profitability arising from category-level markups increases [55]. These findings imply that demand functions need to take into account price endogeneity and heterogeneity.

Nonetheless, these approaches in the empirical Industrial Organization tradition have limitations too. First, simplifying assumptions are often made to make the models mathematically tractable and estimable from available data, because specifying a fully structural model for supply side decision variables can be a challenging task. For example, Villas-Boas and Winer [53] and Yang et al. [55] specify a structural model of demand and a reduced form reaction model of supply. This limited information approach has the advantage of not requiring specific assumptions on the game governing the competitive supply side structure, and thus simplifying the analysis. Second, models in this stream of research require an outside good component, and firms and researchers are assumed to know the size of the market or have reasonable estimates of it, which is often a challenge $[6,44]$. Third, logit models with an outside good incorrectly predict that as the number of alternatives in the market becomes arbitrarily large the Bertrand-Nash markups are bounded away from zero, while the utility of the outside good tends to negative infinity. This is not a trivial problem in light of increasing SKU 
proliferations in many categories. Fourth, in this approach aggregated discrete choice demand models are typically used which presuppose that consumers buy at most one unit of a product among the set offered $[6,13]$. Whereas these models are well suited to describe choices of big-ticket durable goods as in the original applications (e.g., cars), they ignore purchase quantity decisions which are very relevant to studying fast moving consumer goods. Most importantly, these structural models cannot be used to provide normative guidance for decision improvement, because they are built upon the assumption that firms set prices optimally given perfect knowledge of market shares and competitive pricing [15]. For example, while Chintagunta [13] is an elegant application of BLP that allows for the decomposition of retail prices, it suffers from some of the limitations pointed out above, especially that it does not allow room for improvement of retailers' pricing decisions. Our proposed approach shares some similarities with Chintagunta [13], for example, including lagged prices in a reduced-form regression model of current-period prices. But our study differs from his in the fundamental research methodology and objectives. Chintagunta [13] focuses on the potentially outsized role of store brands in driving category profit optimization, derived from the premise that pricing decisions are at market equilibrium. In contrast, our focus is to propose a reduced-form empirical model of pricing decisions and their effects on sales across individual brands without imposing any equilibrium assumptions, and to drive optimal retail markups with the aim at improving the current pricing decisions and category profit.

Imperfect information on manufacturers' pricing strategies and their effects on consumer demand hinder the development of CM. Empirical IO models in marketing often assume that retailers and manufacturers make optimal decisions based on perfect information available to all. In practice, however, manufacturers have much more information about their firms' pricing decisions than retailers. This information asymmetry can lead to asymmetric bargaining power, especially favoring manufacturers of large brands. As a consequence, short-run changes in market prices are dominated by manufacturers' rather than retailers' decisions [36]. These information asymmetries could also very well lead to suboptimal retailer decisions and category profitability.

This sets the stage for our study. We develop a model that offers a comprehensive description of own- and cross-price effects on sales of all brands in a category, as well as of price reaction decisions, and then derive the optimal retail markups for the brands simultaneously to maximize the category profit. We start from the neoclassical log-linear demand system and address three of its major limitations in our proposed model: (a) the large number of cross-price effects, (b) the endogeneity of prices, and (c) infeasibility of full information maximum likelihood estimation (cf. [44], p. 4334). Our approach offers the following contributions over previous studies. (1) Price endogeneity is accounted for in our model by including a behavioral pricing equation that captures manufacturers' pricing decisions based on past sales levels and competitive price responses. Similar to, for example, Yang et al. [55], we use a Bayesian model specification and estimate the supply-side model jointly with the demand functions, accommodating heterogeneity and time-varying trends in sales levels, and accounting for price endogeneity. (2) We use a Bayesian shrinkage approach to dealing with the large number of price parameters, which allows brand-pair specific estimates of the cross-effects. (3) Based on the parameter estimates, we derive the retailers' optimal markups that maximize the category profit over a given time horizon. The standard semi-log or double-log demand functions do not yield interior solutions to the category price optimization problem. Previous research has addressed this by exogenously imposing constraints in deriving the price optima [37], but these yield corner solutions. Instead, we propose the use of a price index in the demand model to capture its effect on category sales, which at the same time enables interior solutions to the category profit maximization problem. We apply a global optimization method to explore the posterior category profit surface in a Bayesian setting. Our procedure resolves the problem of obtaining corner solutions of optimal prices based on the standard log-log or semi-log demand functions with constraints.

\section{Model and Estimation}

We develop a hierarchical Bayesian simultaneous equation system model for weekly store-level sales and price reactions of individual brands in a category. Bayesian estimation of this type of models was pioneered by Kloek and Van Dijk [33] and Zellner [56]. The proposed model follows the neoclassical loglinear form and includes two sets of equations. The first set describes store-level sales of each brand as a function of the brand's own price and the prices of the other brands, as well a category price index and time trend. The second set describes how prices change as a function of observed last-period retail prices and sales volumes. Let $r=1, \ldots, R$ indicate stores; $i=1, \ldots$, $N$ indicate brands; and $t=1, \ldots, T$ indicate weeks. Letting $q_{r}$, ${ }_{t}=\left[q_{r, t, i}\right]$ and $p_{r, t}=\left[p_{r, t, i}\right]$ be vectors of brand-specific sales quantities and retail prices in store $r$ and week $t$, we have the following:

$$
\begin{aligned}
& \ln \left(q_{r, t}\right)=\mu_{r}+\Gamma \ln \left(p_{r, t}\right)+\beta P I_{r, t}+\lambda(t)+\varepsilon_{r, t}, \\
& \ln \left(p_{r, t}\right)=\nu_{r}+A \ln \left(p_{r, t-1}\right)+\Psi \ln \left(q_{r, t-1}\right)+\delta_{r, t},
\end{aligned}
$$

where $\mu_{r}=\left[\mu_{r, i}\right]$ and $\nu_{r}=\left[\nu_{r, i}\right]$ are $N \times 1$ vectors of store-specific constants in the sales and pricing equations, respectively; $\Gamma=\left[\gamma_{i, j}\right], A=\left[\alpha_{i, j}\right]$, and $\Psi=\operatorname{diag}\left[\psi_{i, i}\right]$ are $N \times N$ matrices of 
coefficients of the price effects on sales and coefficients of price-reaction and lagged sales effects on prices, respectively. $P I_{r, t}=\exp \left(w^{\prime} \ln p_{r, t}\right)$ is the Stone price index [50], computed as the weighted average category price in store $r$ and week $\mathrm{t},{ }^{1}$ and $\beta=\left[\beta_{i}\right]$ is a vector of the coefficients of the price index on each brand's sales, which can capture category switching and store switching effects due to changes in the overall category price level. As will be explained shortly, the inclusion of this price index allows interior solutions for the category profit maximization problem. Equation (1) is related to the Almost Ideal Demand System, in which the price index arises as a proxy for consumers' cost of subsistence [18]. We specify storespecific constants, $\mu_{r}$ and $\nu_{r}$, to capture differences in baseline brand sales and prices across stores. We represent store heterogeneity through a random effects specification:

$\mu_{r} \sim N\left(m, V_{\mu}\right), \quad \nu_{r} \sim N\left(n, V_{\nu}\right)$,

where $m=\left[m_{i}\right], n=\left[n_{i}\right]$ are $(N \times 1)$ vectors and $V_{\mu}$ and $V_{\nu}$ are $(N \times N)$ matrices. Flat conjugate multivariate normal priors $N\left(0,10^{5} \times I\right)$ are specified for $m$ and $n$, and inverse-Wishart priors $I W(N+3, I)$ are used for $V_{\mu}$ and $V_{\nu}$. A truncated normal prior $\beta \sim N_{-\infty}^{0}\left(0,10^{5} \times I\right)$ is used for the price index coefficients to constrain them to be negative, which ensures that the category demand cannot go up when any individual prices go to infinity. This enables interior solutions to the category price optimization problem.

Direct estimation of the own- and cross-effects in demand equations $(\Gamma)$ often leads to instability of the estimates due to the large number of cross-price effects to be estimated $\left(N^{2}-N\right.$ coefficients for $N$ brands). To stabilize the estimation, it is often assumed that the cross-effects are the same across brands. An alternative approach is to use aggregate logit models that include an outside good, but these models intrinsically impose a constraint on the nature of the cross-elasticities and render these estimates small (depending on the assumed size of the market). As the size of these cross-estimates reduces artificially, the category price optimization problem reduces to setting the prices of the individual brands independently, which is counter to the fundamental idea of category management. We prefer to freely estimate the cross-effects for all brand pairs, because they would provide a richer picture of cross-brand dynamics in the category and are much needed for implementing CM. To address the estimation problem due to large number of parameters, we employ a Bayesian shrinkage method. We pool both the own- and the cross-effects to their respective category means,

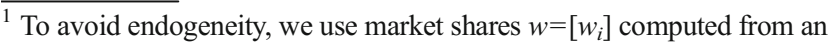
initialization period to weigh prices.
}

following prior practices in hierarchical modeling (e.g., [54]). We specify:

$\operatorname{vec}(\Gamma) \sim N_{0}^{\infty}\left(\operatorname{vec}\left(g_{o} I+g_{c}\left(\iota^{\prime}-I\right)\right), V_{\gamma} \times I\right)$,

where $I$ is an identity matrix of appropriate dimensionality, $\iota$ is a column vector of ones, and $g_{o}, g_{c}$, and $V_{\gamma}$ are scalars. Hierarchical Bayesian estimates of the individual price effects $(\Gamma)$ obtain stability from the category-average own $\left(g_{o}\right)$ and crosseffect coefficients $\left(g_{c}\right)$. The variance of these effects is denoted by $V_{\gamma}$. In addition, the cross-effects are constrained to be positive by drawing them from the normal distribution in (4) truncated at zero (see [11]).

We capture time-dependent variation in brand sales through the smooth vector function, $\lambda(t)=\left[\lambda_{i}(t)\right]$. This function is equivalent to the unobserved product attributes used in aggregated logit models of demand (e.g., $[6,7,14,41])$, but here they also capture seasonal influences on demand, exposure to market level advertising, product availability in the retail chain, shelf space allocation, and other unobserved time-varying variables. Note that we estimate the entire smooth time path here, instead of estimating the location and scale of the distribution of these attributes. Abraham and Lodish $[1,2]$ argue for and implement pre-smoothing techniques to remove trends, seasonality, and the effects of variables omitted from the data. Our formulation is conceptually similar but alleviates a drawback of such pre-smoothing which is that it may also remove part of the relevant own- and crossprice effects. In our approach, a Hierarchical Bayes local polynomial regression smoother is built directly into the model and thus alleviates the problems of pre-smoothing the data $[24,32$, 54]. We assume that the time-sales function can be locally approximated in neighborhood of the time point by a Taylor series expansion:

$\lambda_{i}(t) \approx \sum_{p=0}^{P-1} \int_{t-h}^{t+h}(z-t)^{p} \Omega_{i}(\mathrm{dz})$.

Equation (5) describes $\lambda(t)$ locally by $(P-1)$ th-order local polynomials in the neighborhood $h$. The coefficients of the local polynomial change stochastically over time according to a $P$-variate Wiener process with drift: $\Omega_{i}(s)=\omega_{i}+\Delta^{\prime} B_{i}(s)$, where $B_{i}(s)$ represents a standard $P$-variate Brownian motion, $\omega_{i}$ is a $(P \times 1)$ vector of means, and $V_{\omega}=\Delta^{\prime} \Delta$ a $(P \times P)$ covariance matrix. Local polynomial regression offers good minmax efficiency properties and has negligible boundary effects. We use polynomials of order $P=2$, a global bandwidth of $h=$ 13, and a uniform kernel in our empirical application (cf. [24]) and assume the following priors: $I W(h+3, I)$ for $V_{\omega}$ and $N(0$, $10^{5} \times I$ ) for $\omega_{i}$.

Our reduced-form pricing model given in Eq. (2) includes the effects of own and competitive prices and a brand's previousperiod sales (see [55] as an example of similar formulations). 
Prior research has shown that short-run changes in market prices are dominated by manufacturers', instead of retailers', reactions to competitive offerings [36] and that the effect of retail competition on shelf prices is small [49]. Under the assumption that retail markups in the category remained stable during the time period of interest, which is confirmed by the pattern in our data, the proposed pricing model essentially captures how manufacturers adjust their wholesale prices in response to the observed competitive retail prices and the previous-period sales of its own brand.

Endogeneity of prices will lead to biased parameter estimates in demand models $[8,52]$. We use a reduced-form simultaneous equation specification to address the endogeneity problem, which is similar to the approach by Villas-Boas and Winer [53] and Yang et al. [55]. Yang et al. [55] show that a limited information approach may yield worse fit to empirical data. Nonetheless, the limited information approach tested by them used lagged own prices as instruments in the supply side regression model, which leads to a simple reduced-form approximation. The pricing model we employ here captures a rich pattern of endogenous price setting behaviors and is consistent with findings in previous studies that managers set prices primarily based on past prices and past sales [13, 49].

We pool the price coefficients in the pricing models in a similar manner as in the sales model but do not constrain the individual coefficients $(A)$ as we do not have solid theory on their directions. We specify:

$\operatorname{vec}(A) \sim N\left(\operatorname{vec}\left(a_{0} I+a_{c}\left(\iota \iota^{\prime}-I\right)\right), V_{\alpha} \times I\right)$,

where $a_{0}$ and $a_{g}$ are category-average own- and cross-coefficients, and $V_{\alpha}$ is the variance term. Using results from previous studies [34, 37, 38], we formulate informative priors for the category means in Eqs. (4) and (6): $\left(g_{0}, g_{c}\right)^{\prime} \sim N\left((-2,1)^{\prime}, 0.1 \times I\right)$, $\left(a_{0}, a_{c}\right)^{\prime} \sim N\left((0.5,0.5)^{\prime}, 0.1 \times 1\right)$. Since we have no prior information on variability, we use the following prior variances: $V_{\gamma}^{-1} \sim$ $W(2,1)$, and $V_{\alpha}^{-1} \sim W(2,1)$. Finally, we assume a multivariate normal distribution for the error terms in the sales and price equations $\left(\varepsilon_{r, t, i}, \delta_{r, t}\right) \sim N(0, \Sigma)$. We specify the covariance of the sales and pricing errors in the full model according to a SUR (seemingly unrelated regression) specification (cf. [3]). A conjugate $I W(2 N+3, I)$ prior is used for $\Sigma$. This model can be seen as an extended hierarchical version of the Bayesian multivariate regression model described by Zellner ([56], pp. 224-246).

We employ Markov Chain Monte Carlo (MCMC) methods to estimate the model. Gibbs samplers are used because all prior distributions are standard conjugate distributions. We use 10,000 draws and a burn-in of 5000. The algorithm is started from approximate GLS estimates and convergence is monitored through plots of key parameters against iterates. Results of synthetic data analyses indicated that the algorithm performs well in recovering all true parameters and converges to a stationary distribution well before 5000 draws.

\section{Optimal Retail Markup Decisions}

The category management approach requires a retailer to coordinate decisions on all brands in a category to maximize the category profit. We focus on retail markup decisions in this study. We derive the category profit over a given time horizon based on our model and use a simulation approach to optimizing it (see [19, 42]). Previous work in deriving category profitmaximizing marketing decision variables includes studies by, for example, Montgomery [37], Kopalle et al. [34], and SilvaRisso et al. [47]. Retailers usually make pricing and promotion calendar decisions for a certain time period in advance [14], which is also supported by the pattern in our data, so we assume that the retailer sets a constant unit markup for each brand in the category during the time period, of length $T^{2}$ We detail the optimization problem below.

We optimize the retailer's category profit over a time period of $T$ weeks, using retail markups as decision variables. We assume that the retailer incurs store-specific costs $c_{r}$, sets a constant unit markup $M_{i}$ to the wholesale price of each brand $i$ in the category during the time period of length $T$. The constant markup assumption (within a limited time horizon) is consistent with retailers' common practices and offers an easy-toimplement solution to the category profit maximization problem. The retailer's category profit over $T$ weeks can be expressed as:

$\Pi(M ; \Xi)=\sum_{t=1}^{T} \sum_{r=1}^{R} M^{\prime} q_{r, t}(\Xi)$,

where $M=\left[M_{i}\right]$ is an $N \times 1$ vector of the retailer's unit markups, $\Xi$ represents parameters in the model, and $q_{r, t}(\Xi)$ is the $N \times 1$ vector of sales quantities. In the empirical analysis, $q_{r, t}(\Xi)$ and $\Pi(M ; \Xi)$ are computed as follows. Let $W_{t}=\left[W_{i, t}\right]$ be a vector of wholesale prices at $t, C_{r}^{*}=\left[C_{r, i}^{*}\right]$ be a vector of the retailer's unit variable cost of selling each brand at store $r$. Then, $p_{r, t}=$ $W_{t}+M+C_{r}^{*}$ is the vector of retail prices observed in the data. Let $C_{r, t}=W_{t}+C_{r}^{*}$ be the retailer's total unit variable costs of brands in the category in store $r$ and week $t$. $C_{r, 1}$, i.e., the unit $\operatorname{costs} C_{r, t}$ in the first week of the period of interest, are assumed known to the retailer. We obtain the expressions for prices and sales at $t=1$ by substituting $p_{r, 1}=C_{r, 1}+M$ into Eqs. (1) and (2), initializing with $q_{r, 0}$ as the observed sales in the initial time period and taking exponents. Then, using Eqs. (1) and (2) recursively, we obtain $q_{r, t}(\Xi)$ for $t=2, \ldots, T$ as a function of the parameters $\Xi$. $T$ is determined by the retailer and, in practice, is often set to 3 months (i.e., 13 weeks). Therefore, we chose $T=13$ weeks, which was also used by Neslin et al. [40].

\footnotetext{
${ }^{2}$ In empirical applications of our approach, the length of $T$ can be chosen such that this assumption is likely to hold.
} 
We want to maximize (7) to derive the optimal markups $M^{*}$. There are several complications in doing so through conventional methods. First of all, the standard log-log demand functions in many cases do not yield interior solutions for optimal category pricing (e.g., [37]). This inevitably arises in the presence of positive cross-effects in the sales model (i.e., positive offdiagonal elements in $\Gamma$, which we also observe in our empirical application): if the price of one brand goes to infinity, sales for that brand would become zero, but the sales of one or more other brands would be driven to infinity according to that model, which in turn would drive category sales and profit to infinity. In our model, the inclusion of the category price index in Eq. (1) eliminates this problem: because $\beta$ is constrained to be negative for each brand, as any combination of brand prices goes up, the linear price index effect will eventually dominate the $\log$ brand price effects and drive the category demand downward. Therefore, in our model, it is impossible to drive up category sales by setting the prices of certain brands artificially high. Intuitively, the inclusion of the price index ensures that total sales at the category level decreases with the overall category price level. A second problem in the optimization is that, due to the log-log formulation, the zero-mean error terms do not cancel out when computing the expectations of linear prices, and thus one needs to take into account the stochastic nature of $\vartheta_{r, t}\left(\varepsilon_{r, t, i}, \delta_{t, i}\right)$ in the profit computations. In addition, prices depend on lagged sales, and the exponents of prices appear in the price index term, which complicates the computation of the profit even more.

We adopt a global optimization method to maximize the category profit by exploring the posterior profit function through simulation. At every 5th draw of the Gibbs sampler, $s$, we compute the category profit for $T=13$ weeks, using (1), (2), and (7) at the current parameter values, $\Xi^{s}$, and a draw from $\vartheta_{r, t}^{s} \sim N\left(0, \Sigma^{s}\right)$. We normalize the markups so that the sum of them is equal to their sum in the previous 3 months (i.e., 13 weeks) in the data. While this constraint is not needed to get interior solutions to the category price optimization problem, it has been used previously (cf., [48]) and is intuitively appealing in that it yields markups in the same order of magnitude of previous values and enables a more fair comparison with current practice and other heuristic price setting methods. We use antithetic draws of markups from $M^{v} \sim U(0,1)$ for $v=1, \ldots, V$, where $v$ indicates draws, which greatly improves the efficiency of the optimization. In the empirical application, we choose $V=1024$. This represents eight replications of a $2^{N}$ orthogonal array (see [42]), where $N$ is the number of brands in the category, which is large enough to have sufficient accuracy (see [46]). We then compute the expected profit across the draws of the Gibbs sampler and the markups as $\widetilde{\Pi}\left(M^{v}\right)=\sum_{s=1}^{S} \Pi\left(M^{v}, \Xi^{s}\right) / S$ and determine the optimal markups by solving $M^{-}=\operatorname{argmax}\left[\widetilde{\Pi}\left(M^{v}\right) ; v=1, \ldots, V\right]$. In addition to the optimal markups and profit, we also compute predicted sales, revenue, total cost, and unit cost.

\section{Empirical Application}

\subsection{Data Description}

We use store level scanner data of toothbrushes from the Dominicks retail chain in the Chicago market. ${ }^{3}$ The data include weekly sales, shelf prices, and markups of each brand in the category in 76 stores and 66 weeks. We use 52 weeks for estimation and 13 weeks for holdout validation and optimization, and 1 week is used to initialize the lagged price variables. There are seven brands: Aquafresh, Butler, Colgate, Crest, Oral B, Pepsodent, and Reach. Table 1 shows the means and standard deviations of sales, retail prices, and markups. Note that the markups appear to be very stable during the estimation period.

\subsection{Model Estimation Results}

We present the most relevant parameter estimates in several tables and figures. Figure 1 displays the brand-specific smooth sales-time functions $(\lambda(t))$. It reveals a differentially evolving sales pattern for different brands in the category and shows seasonal variation and possibly holiday-related fluctuations. Some brand sales fluctuate in parallel, such as Pepsodent and Oral B. Other brands reveal more distinct time trends, in particular Aquafresh, Colgate, and Crest. Note that the trends captured here are net of own- and cross-price effects, changes in the overall category price level, and differences among stores. In general, such complicated patterns would be difficult to capture with ARMA specifications and/or seasonal dummy variables. Table 2 shows the posterior mean of the brand-specific sales and price constants $(m$ and $n)$ and their standard deviations ( $\operatorname{diag}\left(V_{\mu}^{1 / 2}\right)$ and $\operatorname{diag}\left(V_{\nu}^{1 / 2}\right)$. It indicates that there is less variation in prices across stores, but a higher level of variation in sales across stores.

Table 3 shows the estimates of the pooled sales and pricing equation parameters $\left(g_{0}, g_{c}, a_{0}\right.$, and $\left.a_{c}\right)$. These can be seen as the category averages of the price effects on demand and the first order price reaction coefficients. The posterior mean of the own-price autoregressive coefficient is 0.47 and significant, ${ }^{4}$ while the mean cross-price reaction effect is not. It appears that there is a significant autocorrelation of prices at the category level, indicating the importance of including own past prices when modeling manufacturer price setting. As to the price effects on sales, the posterior mean own pricedemand effect is -4.35 , and the cross-price effect is 0.49 , both having the expected sign and being significant. Note that the

\footnotetext{
${ }^{3}$ We are grateful to The Kilts Center for Marketing at the University of Chicago for making the data available for academic usage.

${ }^{4}$ We use the word "significant" hereafter to indicate that the $95 \%$ credible interval does not cover zero.
} 
Table 1 Descriptive statistics of the estimation data

\begin{tabular}{|c|c|c|c|c|c|c|}
\hline \multirow[t]{2}{*}{ Brand } & \multicolumn{2}{|c|}{ Weekly sales (units) } & \multicolumn{2}{|c|}{ Shelf price (\$) } & \multicolumn{2}{|c|}{ Markups (\$) } \\
\hline & Mean & S. D. & Mean & S. D. & Mean & S. D \\
\hline Aquafresh & 8.98 & 7.27 & 2.77 & 0.31 & 1.23 & 0.06 \\
\hline Butler & 14.15 & 25.65 & 1.21 & 0.35 & 0.87 & 0.02 \\
\hline Colgate & 24.30 & 15.86 & 2.64 & 0.29 & 1.25 & 0.04 \\
\hline Crest & 16.75 & 11.37 & 2.39 & 0.30 & 0.96 & 0.03 \\
\hline Oral B & 35.25 & 24.37 & 2.54 & 0.21 & 0.94 & 0.02 \\
\hline Pepsodent & 10.55 & 12.09 & 0.92 & 0.11 & 0.47 & 0.02 \\
\hline Reach & 16.70 & 12.11 & 2.40 & 0.26 & 1.07 & 0.04 \\
\hline
\end{tabular}

price coefficients here cannot be interpreted as elasticities because of the inclusion of the price index effect.

Table 4 presents the posterior mean of the coefficients in the pricing equations $(A$ and $\Psi)$. We first focus on $\Psi$, which represents the effect of own last-period sales on price. This effect is positive and significant for six out of the seven brands (with the exception of Aquafresh, for which the coefficient is positive but insignificant). The lagged-sales coefficients are quite large in magnitude, which constitutes strong empirical evidence for price endogeneity. The parameter $A$ represents first-order own and competitive price reaction effects, adjusted for the impact of a brand's endogeneous response to its own lagged-sales. All of the own lagged-price effects are positive and significant, as expected. In general, these coefficients are larger than those of lagged-prices of the other brands. The latter reveal a variety of mostly asymmetric competitive price reaction patterns in the toothbrush category. We focus on the pairs of brands with relatively large coefficients. The most
Table 2 Posterior mean and standard deviations of the store constants in sales and pricing models

\begin{tabular}{llllll}
\hline Brand & \multicolumn{2}{l}{ Store constant of $\log ($ sales) } & & \multicolumn{2}{l}{ Store constant of log (price) } \\
\cline { 2 - 3 } \cline { 6 - 6 } \cline { 5 - 6 } & Posterior mean & $V_{\mu}^{1 / 2}$ & & Posterior mean & $V_{\nu}^{1 / 2}$ \\
\hline Aquafresh & 1.42 & 0.232 & & 1.042 & 0.109 \\
Butler & 1.90 & 0.267 & & 0.584 & 0.111 \\
Colgate & 2.83 & 0.182 & & 0.916 & 0.110 \\
Crest & 2.46 & 0.175 & & 0.893 & 0.110 \\
Oral B & 3.32 & 0.202 & & 0.945 & 0.109 \\
Pepsodent & 1.90 & 0.236 & & -0.073 & 0.110 \\
Reach & 2.60 & 0.230 & & 0.884 & 0.109 \\
\hline
\end{tabular}

The italicized values indicate that the $95 \%$ credible interval does not cover zero

common pattern seems to be a leader-follower relationship, indicated by a strong positive lagged-price coefficient of one brand on the other but a minimal effect the other way around. It includes the following (leader, follower) pairs: (Aquafresh, Butler), (Colgate, Crest), (Colgate, Pepsodent), (Oral B, Pepsodent), (Oral B, Crest), and (Reach, Colgate). Interestingly, the general pattern is that the leader is a higher-priced brand and the follower is a lower-priced brand, with the only exception being the last pair. Another common pattern is that the first brand in a pair has a positive but the second has a negative effect on the other brand, which may indicate that one brand tries to follow while the other tries to avoid head-on competition. Examples are the pairs (Colgate, Aquafresh), (Crest, Aquafresh), and (Crest, Pepsodent).
Fig. 1 Smooth sales-time plots for toothbrush brands

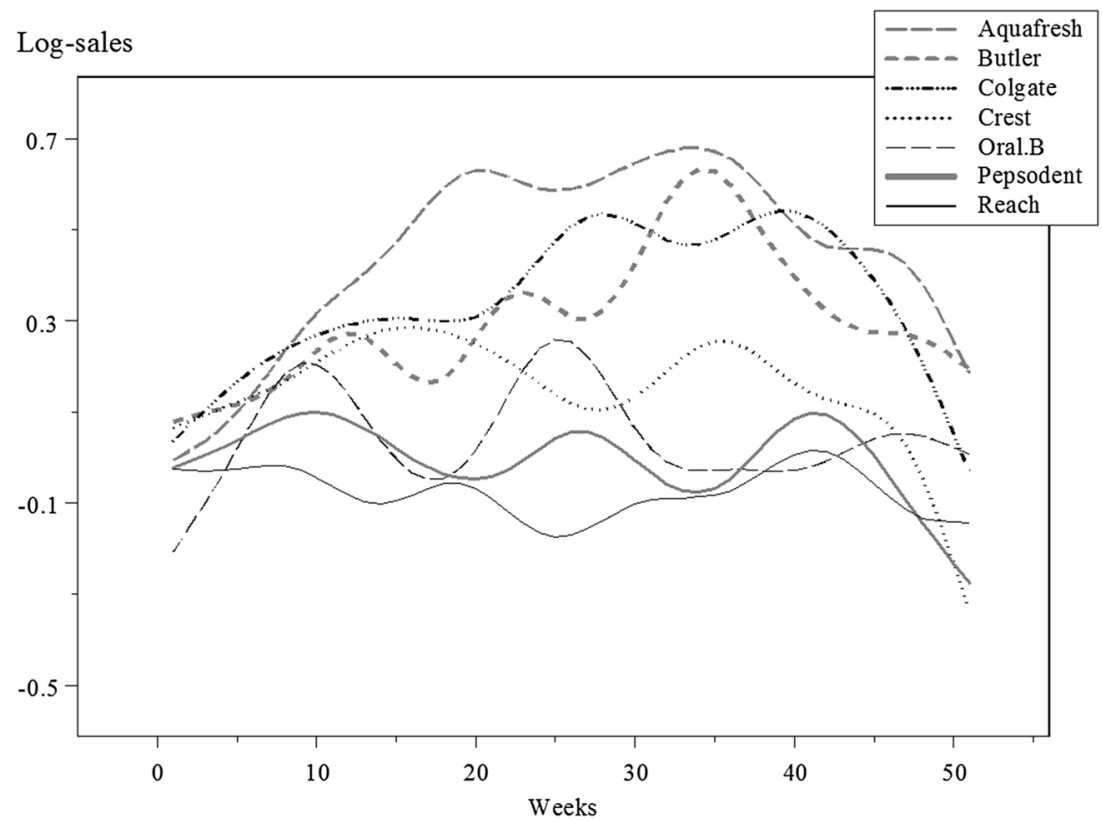


Table 3 Pooled price effects on sales and price reaction effects

\begin{tabular}{lll}
\hline & Own price & Cross price \\
\hline Sales & $g_{0}=-4.35$ & $g_{c}=0.49$ \\
Price & $a_{0}=0.47$ & $a_{c}=0.03$ \\
\hline
\end{tabular}

The italicized values indicate that the $95 \%$ credible interval does not cover zero

Table 5 presents the category price index effects $(\beta)$ and the individual own- and cross-price coefficients $(\Gamma)$ in the demand functions. The price index effect for Butler $(-0.78)$ and Pepsodent $(-0.97)$ are large and significant, showing that their sales go down significantly as the average price level of the category increases. These coefficients imply that store switching may occur as the average price level of the category changes, particularly affecting these two brands. All ownprice coefficients are negative and significant, while a few are fairly large, such as for Aquafresh $(-5.26)$, Oral B $(-5.78)$, and Reach $(-5.22)$. In terms of the cross-price coefficients, there appears asymmetric competition among brands. Higher-priced brands, such as Colgate, Oral B, and Reach seem to have more clout over the others, while low-priced brands such as Butler and Pepsodent appear to be more vulnerable to other brands' influences.

We use 13-week price and sales data for holdout validation of the model, since that corresponds to the period over which we derive the optimal markups. The results are shown in Table 6 . The prices are predicted with an average holdout correlation of $0.60(\mathrm{RMSE}=0.024)$, and the sales are predicted with an average holdout correlation of 0.87 (RMSE $=0.527)$. There are some differences among brands, especially with respect to prices, where the holdout correlations for Crest and Pepsodent are relatively low, but those for Reach and Butler are high. Overall, we consider the predictive performance of the model in the holdout period satisfactory, and we are confident in the optimal markup results over that period, as described below.

\subsection{Optimization Results}

For purposes of comparison, we evaluate our optimal markups versus those derived from three managerially meaningful heuristic procedures which may be used by retailers. We apply the same constraint to the markup allocation for these heuristics: the total markup over all brands is fixed to the actual level in the last 13 weeks of the estimation data. This is a reasonable constraint for a retailer to adopt and it enables a more clear-cut comparison since the total markup for different procedures is the same. The three heuristic procedures are:

- Current practice: uses the actual markups in the holdout period. This reflects the retailer's current practice, for which the precise decision rules are unknown to us.

- Unit cost based: allocates markups proportional to the average unit variable costs $\left(\bar{C}_{i}\right)$ in the last 13 weeks of the estimation data. This scenario reflects the view that the retail markup should increase with a brand's unit variable cost (of which wholesale price is a major component).

- Market share based: allocates markups proportional to the brands' market shares in the last 13 weeks of the estimation data. This allocation method is contrary to a common practice in the retail industry which sets lower markups on higher turnover items.

For each heuristic markup allocation, as well as for the optimal markups, we compute the category profit, sales volume, revenue, total variable costs, and unit variable cost in the holdout period ( $T=13$ weeks). The results are reported in Table 7. It shows that the markups derived from these different procedures differ substantially. Large differences in the markups occur, for example, for Aquafresh, where the optimal markups $(\$ 0.19)$ and those proportional to market share $(\$ 0.38)$ are much lower than those based on current practice $(\$ 1.15)$ or unit costs $(\$ 1.24)$. For Crest, the optimal markup is much lower $(\$ 0.35)$ than that derived from any other procedure, while for Oral B, the optimal markup

Table 4 Posterior means of first order competitive price reaction effects

\begin{tabular}{lllllllll}
\hline Onlof: & Aquafresh & Butler & Colgate & Crest & Oral B & Pepsodent & Reach & Sales $(t-1)$ \\
\hline Aquafresh & 0.45 & -0.07 & 0.14 & 0.14 & -0.05 & -0.07 & -0.12 & 0.08 \\
Butler & 0.29 & 0.73 & -0.02 & 0.00 & -0.11 & -0.01 & -0.08 & 0.59 \\
Colgate & -0.25 & -0.01 & 0.26 & -0.06 & 0.07 & 0.02 & 0.27 & 2.11 \\
Crest & -0.14 & -0.06 & 0.19 & 0.36 & 0.43 & -0.15 & -0.07 & 1.23 \\
Oral B & 0.10 & 0.01 & -0.03 & -0.05 & 0.53 & -0.04 & -0.13 & 0.39 \\
Pepsodent & 0.01 & 0.04 & 0.58 & 0.24 & 0.18 & 0.40 & -0.05 \\
Reach & -0.04 & 0.03 & 0.03 & 0.02 & 0.09 & 0.03 & 0.41 \\
\hline
\end{tabular}

The italicized values indicate that the $95 \%$ credible interval does not cover zero 
Table 5 Posterior means of own- and cross-price coefficients in the sales model

\begin{tabular}{lllllllll}
\hline Onlof: & Aquafresh & Butler & Colgate & Crest & Oral B & Pepsodent & Reach & Price index \\
\hline Aquafresh & -5.26 & 0.71 & 0.09 & 0.87 & 0.73 & 0.37 & 0.28 & -0.06 \\
Butler & 0.74 & -2.45 & 0.33 & 1.96 & 0.45 & 0.57 & 1.67 & -0.78 \\
Colgate & 0.40 & 0.31 & -4.16 & 0.35 & 0.02 & 0.11 & 0.97 & -0.02 \\
Crest & 0.68 & 0.14 & 0.75 & -4.08 & 0.02 & 0.43 & 0.26 & -0.04 \\
Oral B & 0.25 & 0.19 & 0.63 & 0.24 & -5.78 & 0.22 & 0.29 & -0.04 \\
Pepsodent & 0.01 & 0.56 & 0.69 & 0.08 & 1.48 & -3.51 & 1.19 & -0.97 \\
Reach & 0.20 & 0.15 & 0.46 & 0.18 & 0.65 & 0.04 & -5.22 \\
\hline
\end{tabular}

The italicized values indicate that the $95 \%$ credible interval does not cover zero

(\$2.55) is much higher than that based on market share (\$1.97) or unit cost $(\$ 1.24)$.

Table 7 indicates that these different values for the markups result in substantial differences in profits. Allocating markups proportional to unit costs is only slightly better than the current practice in terms of profits, which are around $\$ 110,000$ and $\$ 108,000$, respectively. It is also clear that allocating markups proportional to the brands' market shares is the best-performing heuristics among the three and yields a profit around \$132,000 in the holdout period. Finally, the optimal allocation of markups results in the highest profit, around $\$ 149,000$.

Interestingly, the performance of the market sharebased markup allocation is closest to the optimal procedure, for this category. The allocation of markups proportional to market share would increase the category profit by $21.8 \%$ in the coming 3 months, while the optimal markup settings would increase it by $37.7 \%$ over the current practice. This may be of interest to practitioners in the retail industry if the finding can be generalized. But setting the markups to optimize category profit is clearly better. A comparison of the optimal markups with current practice suggests that current practice yields a substantially lower spread of the markups. The largest brand Oral B, is underpriced, while the smallest brand, Aquafresh, is overpriced by the retailer. This explains why setting markups proportional to market shares would increase category profit and calls into question the common practice in the retail industry of setting lower markups on high turnover items and higher markups on low turnover items. This practice may well be based on brand-by-brand considerations. If we take the perspective of managing the entire category and account for retail competition, interdependencies of sales of brands and manufacturer marketing activity within the category, this practice seems to be misguided.

We further explore the causes for the differences in profitability. Table 7 indicates that sales levels for the three heuristic pricing procedures are not very different, and predicted category sales for the optimal markups are only $6.4 \%$ higher than that for the current practice. Correspondingly, category revenue under the optimal markups is also only slightly higher than for the heuristically derived markups, e.g., $1.0 \%$ higher than the current practice. But, interestingly, total variable cost and thus also unit variable cost are much lower for the optimal markups. Unit costs are $31.5 \%$ lower if the retailer would apply the optimal markups ( $\$ 0.89$ ), as compared to continuing the current practice $(\$ 1.30)$.

These results reveal that the retail profit can be raised without increasing sales volume or revenue. Rather, the higher profit seems to be achieved by setting markups optimally so that (1) a larger proportional of revenue is generated by high markup brands and (2) wholesale prices are driven down by manufacturer competition. The second point is particularly interesting. It underscores the importance of including the price setting component in the model when forecasting future sales and in deriving the optimal category prices for a retailer. Prior econometric work on category management has mostly relied on a flexible specification for consumer demand. This parsimonious specification ignores the fact that retailer profitability relies not only on consumer demand but also on manufacturers who set prices dynamically.
Table 6 Thirteen-week holdout correlations

\begin{tabular}{lllllllll}
\hline & Aquafresh & Butler & Colgate & Crest & Oral B & Pepsodent & Reach & Overall \\
\hline Sales & 0.81 & 0.58 & 0.87 & 0.86 & 0.85 & 0.81 & 0.77 & 0.87 \\
Price & 0.25 & 0.92 & 0.47 & 0.21 & 0.50 & 0.34 & 0.78 & 0.60 \\
\hline
\end{tabular}


Table 7 Thirteen-week category profit evaluation

\begin{tabular}{lllll}
\hline $\begin{array}{l}\text { Brand/markups } \\
(\$)\end{array}$ & $\begin{array}{l}\text { Current } \\
\text { practice }\end{array}$ & $\begin{array}{l}\text { Unit cost } \\
\text { based }\end{array}$ & $\begin{array}{l}\text { Market share } \\
\text { based }\end{array}$ & Optimal \\
\hline Aquafresh & 1.15 & 1.26 & 0.38 & 0.19 \\
Butler & 0.86 & 0.72 & 0.53 & 0.63 \\
Colgate & 1.24 & 0.99 & 1.45 & 1.20 \\
Crest & 0.93 & 1.08 & 0.92 & 0.35 \\
Oral B & 0.92 & 1.24 & 1.97 & 2.55 \\
Pepsodent & 0.48 & 0.34 & 0.63 & 0.38 \\
$\quad$ Reach & 1.10 & 1.04 & 0.78 & 1.39 \\
Gross profit (\$) & $107,941.97$ & $110,074.21$ & $131,538.96$ & $148,642.71$ \\
Sales (units) & $110,030.60$ & $108,725.66$ & $111,178.02$ & $117,062.01$ \\
Revenue $(\$)$ & $250,549.54$ & $246,402.91$ & $248,731.01$ & $252,957.91$ \\
Total variable & $142,607.57$ & $136,328.70$ & $117,192.04$ & $104,315.20$ \\
$\quad$ cost $(\$)$ & & & & \\
Unit variable & 1.30 & 1.25 & 1.05 & 0.89 \\
$\quad$ cost (\$) & & & & \\
\hline
\end{tabular}

\section{Discussion and Future Research}

Our study is a response to the needs in the retail industry for sophisticated yet practical model-based decision support tools for implementing category management. Our analysis indicates that adopting a model-based approach can improve category profit over the retailer's current practice by as much as $30-40 \%$. This is, of course, a short-run result and could be altered if other retailers followed suit. In addition, our empirical results suggest a simple and effective way for retailers to set markups based on historical sales data and improve profitability over the current practice, i.e., allocating markups proportional to market shares. Our analysis indicates that larger share brands should be set with higher markups than what is done in the current practice and that a common practice in the retail industry of charging lower markups for high turnover items may not serve the retailer's best interest from a CM perspective. Of course, more empirical tests of the generalizability of these findings are needed in future research, and we believe it is particularly important to examine it across a wide range of categories.

The alternative markup setting methods analyzed in our study were formulated under the constraint that the total markup remains unchanged relative to the last quarter. A retailer may wish to modify this constraint based on knowledge of the marketplace or its own specific strategic purposes for the category. For example, if the retailer is confident that a certain increase in the total markup will not lead to adverse effects on store traffic, as judged from the price index estimates of the model, then the total markup can be set higher and the brand-specific markups can be allocated accordingly. The proposed approach is based on the assumptions that the retailer sets a constant unit markup for each brand in the category during the prefixed time period and that manufacturers pricing decision rules remain stable across the that period. These assumptions could be relaxed and we leave it as a direction for future research.

Previous studies on retail category management have often taken the game-theoretic approach. Studies based on the game theory approach and those built upon econometric models are both needed in exploring this new research area. Interestingly, our empirical results are consistent with the analytical results by Basuroy et al. [4]. They also find that CM can increase a retailer's category profit without increasing total sales of the category, a finding echoed by Cachon and Kök [12], Hall et al. [28], and Gooner et al. [27]. And more importantly, completely in accordance with our findings, Basuroy et al. [4] show via their game theoretical model that the profit gain is achieved through lower wholesale prices under the scenarios where a retailer adopts a $\mathrm{CM}$ perspective. We find the convergence of the results from two independent streams of research quite encouraging.

In computing the expected category profit based on our demand and price setting model, we have assumed that short-term price fluctuations in the marketplace are driven by manufacturers' pricing decisions, which implies $100 \%$ pass-through of trade promotions by the retailer. Studies have shown that retail pass-through is generally below $100 \%$ (e.g., $[9,39])$. Future research should incorporate pass-through decisions as an integrated component of $\mathrm{CM}$ decision variables.

It has been suggested that the adoption of CM is most effective for categories for which cross-effects are high and not necessarily for categories with high sales volumes [57]. Taking the application of our model one step further, it could be applied to identify the categories where CM is most effective. It would enable a retailer to better coordinate marketing activities across categories. To take the issue even further, one would need to consider a category's strategic role in a retailer's overall planning [12]. Although profit generation is the primary goal for the vast majority of product categories in a retailer's assortment, other priorities might be given to certain categories. For example, the so-called loss leader categories (i.e., categories that are sold nearly at costs) are commonly used by retailers to build store traffic instead of to maximize profits of these categories. The objective function needs to be adjusted according to the strategic roles designed for the categories. Although the ultimate goal of category management should be to improve the overall performance of the retailer instead of to maximize the impact of any one category in isolation, we believe that the approach presented in this study is a valuable step in advancing the effectiveness of category management. 
Acknowledgments The authors are grateful to The Kilts Center for Marketing at the University of Chicago for making available the data used in this study.

\section{References}

1. Abraham MM, Lodish LL (1987) PROMOTER: an automated promotion evaluation system. Mark Sci 6(2):101-123

2. Abraham MM, Lodish LL (1993) An implemented system for improving promotion productivity using store scanner data. Mark Sci 12(3):248-269

3. Allenby GM, Jen L, Leone RP (1996) Economic trends and being trendy: the influence of consumer confidence on retail fashion sales. $\mathrm{J}$ Bus Econ Stat 14(1):103-111

4. Basuroy S, Mantrala MK, Walters RG (2001) The impact of category management on retailer prices and performances: theory and evidence. J Mark 65:16-32

5. Benzie E, Pearce MR (1995) An introduction to category management, Ivey Management Service, Reprint 9A95A005

6. Berry ST, Levinsohn J, Pakes A (1995) Automobile prices in market equilibrium. Econometrica 3(4):841-890

7. Besanko D, Dubé JP, Gupta S (2005) Own-brand and cross-brand retail pass-through. Mark Sci 24(1):123-137

8. Besanko D, Gupta S, Jain D (1998) Logit demand estimation under competitive pricing behavior: an equilibrium framework. Manag Sci 44(11):1533-1547

9. Blattberg RC, Briesch R, Fox EJ (1995) How promotions work. Mark Sci 14(3):G122-G132

10. Blattberg RC, George E (1991) Shrinkage estimation of price and promotional elasticities: seemingly unrelated equations. J Am Stat Assoc 86:304-315

11. Boatwright P, McCulloch R, Rossi PE (1999) Account-level modeling for trade promotion: an application of a constrained parameter hierarchical model. J Am Stat Assoc 94(448):1063-1073

12. Cachon GP, Kök AG (2007) Category management and coordination in retail assortment planning in the presence of basket shopping consumers. Manag Sci 53(6):934-951

13. Chintagunta PK (2002) Investigating category pricing behavior at a retail chain. J Mark Res 39(2):141-154

14. Chintagunta PK, Dubé JP, Singh V (2003) Balancing profitability and customer welfare in a supermarket chain. Quant Mark Econ 1(1):111-147

15. Chintagunta PK, Erdem T, Rossi PE, Wedel M (2006) Structural modeling in marketing: review and assessment. Mark Sci 25(6): 604-616

16. Chintagunta PK, Song I, Bonfrer A (2002) Investigating the effects of store brand introduction on retailer demand and pricing behavior. Manag Sci 48(10):1242-1267

17. Choi SC (1991) Price competition in a channel structure with a common retailer. Mark Sci 10:271-296

18. Deaton A, Muellbauer J (1980) An almost ideal demand system. Am Econ Rev 70:312-326

19. Dorfman JH (1995) A numerical Bayesian test for cointegration of AR processes. J Econ 66(1):289-324

20. Du R, Lee E, Staelin R (2005) Bridge, focus, attack, or stimulate: retail category management strategies with a store brand. Quant Mark Econ 3(4):393-418

21. Dubé JP, Hitsch GJ, Rossi PE, Vitorino MA (2008) Category pricing with state-dependent utility. Mark Sci 27(3):417-429

22. Dupre K, Gruen TW (2004) The use of category management practices to obtain a sustainable competitive advantage in the fastmoving-consumer-goods industry. J Bus Ind Mark 19(7):444-459
23. Ellickson PB, Misra S (2008) Supermarket pricing strategies. Mark Sci 27(5):811-828

24. Fan J, Gijbels I (1996) Local polynomial regression and its applications. Chapman and Hall, London

25. Fox EJ, Postrel S, Semple JH (2009) Optimal category pricing with endogenous store traffic. Mark Sci 28(4):709-720

26. Gasmi FJ, Laffont J, Vuong Q (1992) Econometric analysis of collusive behavior in a soft-drink market. J Econ Manag Strateg 1:277311

27. Gooner RA, Morgan NA, Perreault WD Jr (2011) Is retail category management worth the effort (and does a category captain help or hinder)? J Mark 75(5):18-33

28. Hall JM, Kopalle PK, Krishna A (2010) Retailer dynamic pricing and ordering decisions: category management versus brand-by-brand approaches. J Retail 86(2):172-183

29. Ingene CA, Parry ME (2004) Mathematical models of distribution channels (Vol. 17). Springer Science \& Business Media

30. Ingene CA, Parry ME (2007) Bilateral monopoly, identical distributors, and game-theoretic analyses of distribution channels. J Acad Mark Sci 35(4):586-602

31. Kadiyali V, Vilcassim NJ, Chintagunta PK (1996) Empirical analysis of competitive product line pricing decisions: lead, follow, or move together? J Bus 9:459-487

32. Kalyanam K, Shively TS (1998) Estimating irregular pricing effects: a stochastic spline approach. J Mark Res 35:16-29

33. Kloek T, Van Dijk HK (1978) Bayesian estimates of equation system parameters: an application of integration by Monte Carlo. Econ: J Econ Soc 46:1-19

34. Kopalle PK, Mela CF, Marsh L (1999) The dynamic effect of discounting on sales: empirical analysis and normative pricing implications. Mark Sci 18(3):317-332

35. Lal R (1990) Price promotions: limiting competitive encroachment. Mark Sci 9(3):247-262

36. Leeflang PSH, Wittink DR (1996) Competitive reaction versus consumer response: do managers overreact? Int J Res Mark 13:103-119

37. Montgomery AL (1997) Creating micro-marketing pricing strategies using supermarket scanner data. Mark Sci 16(4):315-337

38. Montgomery AL, Rossi PE (1999) Estimating price elasticities with theory based priors. J Mark Res 36:413-423

39. Moorthy S (2005) A general theory of pass-through in channels with category management and retail competition. Mark Sci 24(1):110 122

40. Neslin SA, Powell SG, Schneider-Stone L (1995) The effects of retailer and consumer response on optimal manufacturer advertising and trade promotion strategies. Manag Sci 41:749-766

41. Nevo A (2001) Measuring market power in the ready-to-eat cereal industry. Econometrica 2:307-342

42. Niederreiter H (1992) Random number generation and quasi-Monte Carlo methods. SIAM, Philadephia

43. Nijs VR, Srinivasan S, Pauwels K (2007) Retail-price drivers and retailer profits. Mark Sci 26(4):473-487

44. Reiss PC, Wolak FA (2007) Structural econometric modeling: rationales and examples from industrial organization. Handb Econ 6: $4277-4415$

45. Roy A, Hanssens DM, Raju JS (1994) Competitive pricing by a price leader. Manag Sci 40:809-823

46. Sándor Z, András P (2004) Alternative sampling methods for estimating multivariate normal probabilities. J Econ 120(2):207234

47. Silva-Risso JM, Bucklin RE, Morrison DG (1999) A decision support system for planning manufacturers' sales promotion calendars. Mark Sci 18(3):274-300

48. Song I, Chintagunta PK (2006) Measuring cross-category price effects with aggregate store data. Manag Sci 52(10):1594-1609 
49. Srinivasan S, Pauwels K, Nijs V (2008) Demand-based pricing versus past-price dependence: a cost-benefit analysis. J Mark 72(2):1527

50. Stone JRN (1953) The measurement of consumers' expenditure and behaviour in the United Kingdom, 1920-1938, Vol. 1, Cambridge

51. Sudhir K, Datta S (2008) Pricing in marketing channels. In: Rao $\mathrm{V}$ (ed) Handbook of pricing. Edward Elgar Publishers, Northampton

52. Vilcassim NJ, Kadiyali V, Chintagunta PK (1999) Investigating dynamic multifirm market interactions in price and advertising. Manag Sci 45(4):499-518
53. Villas-Boas JM, Winer RS (1999) Endogeneity in brand choice models. Manag Sci 45(10):1324-1338

54. Wedel M, Zhang J (2004) Analyzing brand competition across subcategories. J Mark Res 41(4):448-456

55. Yang S, Chen Y, Allenby GM (2003) Bayesian analysis of simultaneous demand and supply. Quant Mark Econ 1(3):251275

56. Zellner A (1972) An introduction to Bayesian inference in econometrics. Wiley, New York

57. Zenor MJ (1994) The profits benefits of category management. J Mark Res 31:202-213 